This is the peer reviewed version of the following article:

Brown, S. and Harris, M.N. and Prendergast, J. and Srivastava, P. 2015. Pharmaceutical drug misuse: are industry of employment and occupation risk factors? 46 (5-6): pp. 398-417.,

which has been published in final form at http://doi.org/10.1111/irj.12115

This article may be used for non-commercial purposes in accordance with Wiley Terms and Conditions for Self-Archiving at http://olabout.wiley.com/WileyCDA/Section/id-

820227.html\#terms 


\title{
Pharmaceutical drug misuse: Are industry of employment and occupation risk factors?
}

\author{
Sarah Brown, University of Sheffield, UK \\ Mark N. Harris, Curtin University, Australia \\ Jake Prendergast, Curtin University, Australia \\ Preety Srivastava, RMIT, Australia
}

September 2015

\begin{abstract}
We explore the misuse of pharmaceutical drugs in the Australian workforce, focusing on whether any differences exist between workers in particular industries or occupations. In terms of industry, being employed in hospitality is positively associated with pharmaceutical drug misuse, while being employed in finance, insurance and retail is inversely related. In terms of occupation, we find that being a labourer is positively related to misuse of pharmaceutical drugs, while being employed in managerial, professional, sales, clerical or administrative roles is associated with a lower tendency. Further analysis of occupational effects revealed that being in a blue collar occupation, as a whole, is positively related to pharmaceutical drug misuse relative to white collar employment. Moreover, being employed in higher status roles is associated with a lower likelihood of such behaviour. Our findings imply that particular workplace pressures, cultural norms and/or working conditions might be influential factors behind workers’ drug misuse.
\end{abstract}

Key Words: Industry; labour market participation; occupation; pharmaceutical drugs; illicit drugs

JEL: C5, D1, I1, J00

Acknowledgements: The authors are grateful to the Bankwest-Curtin Economics Centre and the Australian Research Council for their generous financial support. The usual caveats apply. They would also like to thank Dr Leonora Risse for excellent research assistance. 


\section{Pharmaceutical drug misuse: Are industry of employment and occupation risk factors?}

\section{Introduction}

Drug consumption is, understandably, an area of key policy concern in many countries, given the considerable costs that it imposes on individuals, their families, workplaces and the wider community. However, while the use of illicit drugs has been researched extensively ${ }^{1}$, there has been relatively less attention placed on the misuse of pharmaceutical drugs that can be legally obtained over-the-counter or with a prescription. The use of pharmaceutical drugs for non-medical purposes has become a subject of concern in many countries including Australia: the Australian Institute of Health and Welfare reported that, in 2010, 4.2\% of Australians over the age of 12 had used psychotherapeutic prescription drugs for non-medical purposes (AIHW 2011). In the US, the use of prescription drugs for non-medical purposes has been on a constant rise in recent years with the latest National Survey on Drug Use and Health indicating 6.5 million Americans (or 2.5\% of the population aged 12 or older) having reported using psychotherapeutic prescription drugs non-medically in 2013 (NSDUH 2013). The death toll from overdose of such drugs is rising rapidly. Over 800 people died from fatal overdose of prescription drugs such as painkillers and tranquillisers in the UK in 2012, according to the Office for National Statistics, compared with around 700 who fell victim to heroin and cocaine abuse.

There are reasons to believe that the misuse of pharmaceutical drugs is an ongoing trend and the rise appears to result from the increased and easy availability of these drugs, growing social acceptance, and more importantly, the perception that they are safe (Friedman 2006, McCarthy 2007, Twombly and Holtz 2008). Moreover, pharmaceutical drug misuse is particularly difficult to monitor and control given the availability of many drugs both overthe-counter and online (Nielsen and Barratt 2009). The growing number of online pharmacies has developed a new and rapidly expanding market place for pharmaceuticals that may help to explain the increased rates of use reported in recent survey data (Compton and Volkow 2006). As pharmaceutical drug misuse becomes more prevalent, it becomes increasingly important to understand the reasons behind their consumption, so that effective strategies can be developed

\footnotetext{
${ }^{1}$ Empirical studies have played an important role in helping to identify the socioeconomic and demographic factors associated with the consumption of illicit drugs such as marijuana and cocaine (Grossman and Chaloupka 1998, Farrelly et al. 1999, Ramful and Zhao 2009) as well as legal addictive goods such as alcohol and cigarettes (Chaloupka and Pacula 1999, Cameron and Williams 2001, Farrelly et al. 2001).
} 
to curb this trend. Helping to address the current lack of research into this topic, this paper examines the underlying drivers of pharmaceutical drug misuse in Australia. Specifically, we explore this issue in the context of the workforce and investigate whether there are particular industries or occupations in which workers are more prone to engage in pharmaceutical drug misuse.

Given our focus on industry and occupation effects, it is important to consider the prevailing legislative regulatory settings that can also shape workers' drug-taking behaviour. In Australia, legislation exists which prohibits workers from carrying out their job duties under the influence of drugs or alcohol, largely enacted for a specific industry or jurisdiction (for example, the Western Australia Mines Safety and Inspection Regulation 1995). In addition, most jurisdictions have standards, codes and guidelines that are designed to assist employers to formulate their own workplace policies, including how to implement safeguards to manage employees who take prescription medications. In Western Australia (WA), for example, guidelines are administered through WorkSafe WA. Many employers have responded to this legislation by implementing their own workplace drug testing procedures.

While workplace drug testing is fairly common across the Australian workforce generally, it is concentrated in industries where safety is of critical importance, such as mining, transportation, and police and correctional services. In more recent years, the workplace drug testing appears to have become a more acceptable practice in Australia, in light of a 2011 decision by Fair Work Australia that workplace drug testing - despite not being spelt out explicitly as an employer's right in legislated contracts - is legal in Australia as it enables employers to fulfill their duty of care and OHS obligations. Following this decision, some union divisions have come to voice support for mandatory testing. The existence of these legislation and workplace drug testing procedures would be expected, all other factors equal, to curtail the rates of drug misuse within the workplace. We are aware that some aspects of relevant legislation changed during the period under analysis which effectively tightened their stringency (such as a move within some sub-industries to permit the use of oral fluid testing in addition to urine testing).

Our focus on the workforce yields two insights into the link between drug misuse and the labour market. Firstly, since we know that one of the main costs of drug consumption is the loss in productivity in the workplace - as workers who engage in drug misuse are more likely to absent or be unfit for work or retire prematurely - we can identify segments of the 
labour market that are more likely to experience these economic costs. Secondly, since we are also aware that workers' behaviours can be influenced by workplace-related factors - such as the working conditions, peer pressure or cultural norms prevailing within a particular industry or occupation - we identify potential drivers behind pharmaceutical drug misuse that could be related to features of the workplace. To place the consumption of pharmaceutical drugs into a wider context, we also look at the prevalence of three other types of illicit drugs commonly used in Australia: marijuana (or cannabis), amphetamines (or speed) and ecstasy.

\section{Background}

From an economic perspective, both licit and illicit drug consumption has been shown to have significant impacts on the labour market and vice versa. However, to the best of the authors' knowledge, evidence linking prescription drugs to the labour market is non-existent. High rates of drug use in the workforce are of particular concern as prior empirical works have found strong links between drug use, and decreased wages and productivity (see, for example, Register and Williams 1992, Zarkin et al. 1998, MacDonald and Shields 2000, MacDonald and Pudney 2000, DeSimone 2002, Lye and Hirschberg 2010).

The labour market factors that drive drug consumption have equally received significant attention in the literature (Ames and Grube 1999, Ames et al. 2000, Bacharach et al. 2002, Zhang and Snizek 2003). Managerial control, workplace culture, stress levels and the enforcement of policies were seen as factors influencing the consumption of alcohol in workforces in Bacharach et al. (2002). Workplace culture was seen as a determining factor as workers develop assumptions about what constitutes appropriate drinking behaviour from their peers. These assumptions can often transform into social expectations that lead to pressure on workers to conform (Bacharach et al. 2002). This study echoed the statement of Boye and Jones (1997, p.175) that "many studies have shown that the norms of the work group can influence the level of counterproductive behaviour engaged in by employees”. In terms of job characteristics, steady employment or job security were found to be correlated with alcohol and drug use (Zhang and Snizek 2003).

Workplace factors that lead to drug use may also be industry and occupation specific, posing issues for productivity. For instance, Conway et al. (1981) found high occupational stress to be positively associated with the consumption of cigarette and coffee but negatively associated with alcohol consumption. The differing cultural norms and attitudes of employees 
within an industry may allow a greater level of drug use in employees than is present in other industries (Larsen 1994). Some studies have explored such industry and occupation differential effects on drug use.

In terms of industry differences, hospitality workers have been identified as a high risk group with regard to drug use at the workplace (Eade 1993, Pidd et al. 2011). Studies have also identified construction workers and those employed in the arts and recreational industry as other high risk groups for drugs (see, for example, Banwell et al. 2006, Berry et al. 2007, Du Plessis and Corney 2011, Biggs and Williamson 2012). Du Plessis and Corney (2011) identified peer pressure as a significant factor in the increased drug use witnessed in the construction industry. As many people participate in after work socialising with colleagues which may include drinking and other activities - it is possible that drug use could be affected by peer pressure exerted by work colleagues. In other words, socialising with people from the workplace which has a high rate of drug consumption could make an individual more likely to participate in drug consumption.

The positive relationships identified in the construction industry pose a particular concern given the effect that drug use can have on decision making abilities both during and after use (Vaidya et al. 2012). According to Biggs and Williamson (2012), a potential source of the increased drug use in the construction industry is the employee's inability to cope with the lifestyle that comes about as a result of project-to-project, transient work. The stop-start nature of the construction industry provides many workers with large periods of free time at some stages and long working hours at other stages. There are concerns that these free periods coincide with the use of both licit and illicit drugs (Biggs and Williamson 2013). Additionally, the construction industry is very masculine in culture, requires hard physical labour and can be a stressful environment - factors that have been associated with high drug use (Banwell et al. 2006).

A high likelihood of drug use among sections of the agriculture industry has previously been identified in studies (see, for example, Evans et al. 2005). This was partly attributed to self-esteem issues which stemmed from a feeling of being undervalued as the industry lacks appropriate career paths and adequate training (Evans et al. 2005). Access to prescription-type substances in the workplace is a unique feature of the practice of health professionals. Trinkoff et al. (1999) found evidence of misuse of such drugs among nurses who had easy access. 
With regard to occupation, it has been found that use of drugs with stimulant properties is common among truck drivers in particular, in order to maintain energy throughout long-haul trips (Couper et al. 2002, Silva et al. 2003). Sustained periods of driving exert considerable mental strain on the driver and the job is therefore likely to be fatiguing (Krueger 1989). Research has shown that vigilant tasks such as driving become more taxing on the individual in the early hours of the morning when many transport employees complete long distance drives (see, for example, Folkard and Monk 1979, Monk and Folkard 1985). Some studies have reported drug and alcohol use in the workplace to be more common in blue collar jobs than in white collar occupations (Gleason et al. 1991, Zhang and Snizek 2003).

It is commonly known that the type of drug consumed varies by social class. For instance, tobacco and most illicit drugs are mostly associated with lower socioeconomic groups (Galea et al. 2004) while alcohol and cocaine users typically belong to both ends of the socio-economic ladder. For instance, cocaine users often come from middle and upper socioeconomic status groups, live in affluent areas, are more educated, and are employed in white collar jobs and creative occupations (ACC 2006, Hando et al. 1997). Given that in certain industries (such as construction and mining) and professions (such as labourers) job recruitment is usually done from a common milieu or neighbourhood, it is quite likely that the type and levels of drug taking will reflect social class. Thus, in addition to the nature of the industries and occupations discussed above, social background is also likely to explain drug use. $^{2}$

In summary, in contrast to the academic interest in other drugs, there is a distinct lack of existing literature on the misuse of pharmaceutical drugs, which implies limited understanding of the determinants of consumption of such drugs for individuals that are not predisposed to use due to dependence following a previous medical condition. Such a lack of research in this area may reflect a shortage of suitable data. Hence, we explore the determinants of pharmaceutical drug misuse and focus on potential industry and occupation effects, which have been associated with the consumption of other drugs. Due to the difficulty in controlling misuse of legal, i.e. pharmaceutical, drugs further knowledge of these determinants will potentially have an important impact on providing necessary and effective policy initiatives.

\footnotetext{
${ }^{2}$ In the econometric analysis that follows, we control for socioeconomic status using income and education.
} 


\section{Data}

Data are obtained from the Australian National Drug Strategy Household Surveys (NDSHS) where information on licit and illicit drug consumption are collected from a nationally representative sample of the non-institutionalised Australian population aged 12 and over. A random sampling of households geographically is ensured through the use of a multi-stage, stratified area sample design (AIHW 2011). There have been several surveys completed since 1985 and the data have been used in a number of previous studies on licit and illicit drug consumption (see, for example, Cameron and Williams 2001, Harris and Zhao 2007, Ramful and Zhao 2009, Srivastava 2010). The NDSHS also provides information on drug attitudes and behavior, and a host of demographic and socioeconomic information on the respondents.

In this paper, the four most recent surveys (2001, 2004, 2007 and 2010) have been pooled together given their consistency (NDSHS 2010). We restrict the analysis to individuals who are of working age and thus limit our observations to 20 to 65 years old (the retirement age in Australia is 65). After omitting missing values the sample of working age individuals consists of 66,430 observations. Information on use of pharmaceutical drugs for non-medical purposes is collected using the following question: Have you used [pharmaceutical drug] for non-medical purposes in the last 12 months? This question is asked separately for four different pharmaceutical types: pain killers and analgesics, tranquillisers and sleeping pills, steroids and other opiates including morphine and pethidine. ${ }^{3}$

Looking at the misuse of such legally-prescribed or over-the-counter drugs in Australia, we find that over the period 2001-2010 around 3.7\% of all working-age individuals had consumed some form of pharmaceutical drug for non-medical purposes within the year prior to the survey. When we narrow the sample to only those who are employed in the workforce - which is the focus of our analysis - the rate of pharmaceutical drug misuse for non-medical purpose averages to 3.4\% for the period 2001 through 2010, of which users of painkillers and analgesics accounted for the largest portion, followed by tranquillisers and sleeping pills (see Figure 1). In comparison, cannabis is relatively more prevalent than pharmaceutical drug misuse, with around $10 \%$ of the Australian workforce using this illicit

\footnotetext{
${ }^{3}$ As stated by a referee, it is important to acknowledge that such a question may invite a 'socially desirable/acceptable' response and consequently responses may be biased. Arguably, the extent of such bias may be common within the respondent group meaning that, although absolute response rates may be unreliable, relative differences may be reliable in this context.
} 
drug while ecstasy and speed are relatively less prevalent, with usage rates of $2.7 \%$ and $2.5 \%$ respectively.

Figure 1: Rates of pharmaceutical drug misuse among working-age Australians, 2001-2010

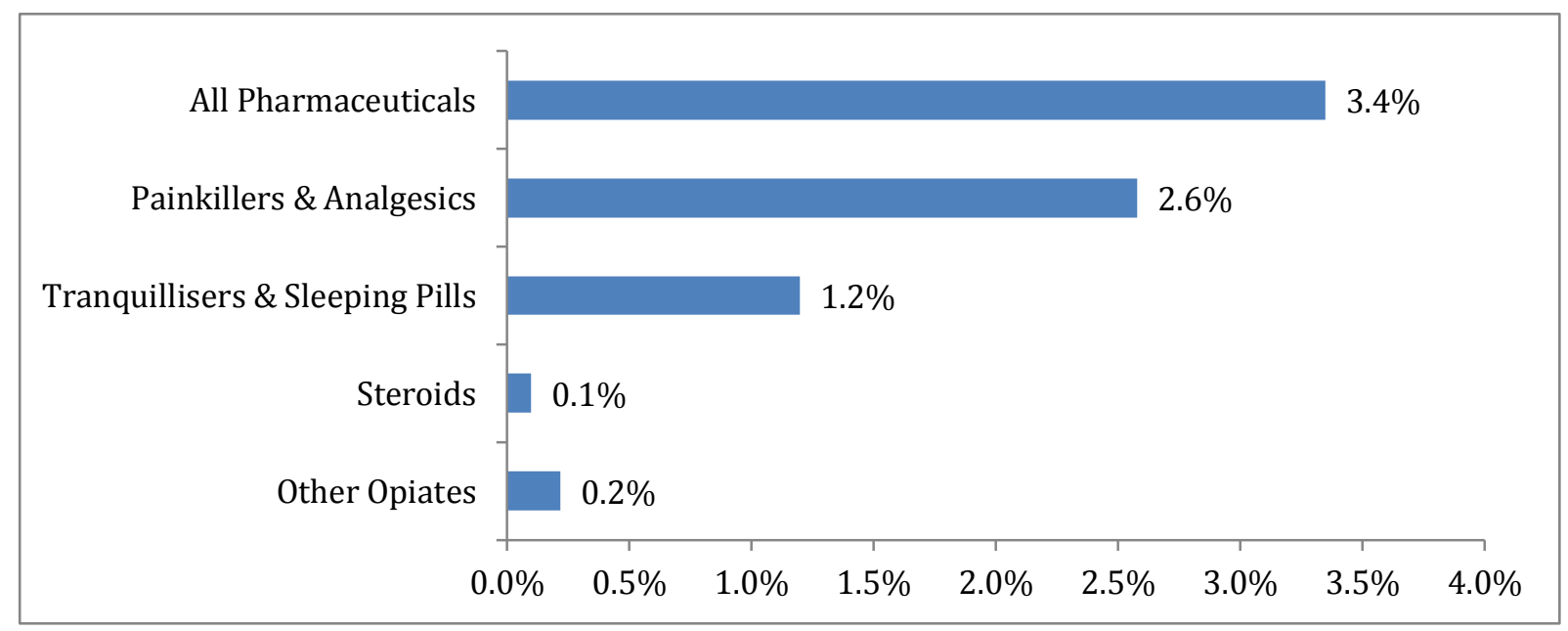

\section{Methodology}

In order to avoid potential sample selection bias (since to explore industry and occupation effects, by definition, we focus on employees only), we use a Heckman sample selection ('Heckit') model, specifically involving two equations: participation in pharmaceutical drug consumption and a selection equation that determines whether an individual is employed. Note that here, and elsewhere, the term 'pharmaceutical or prescription drug consumption' specifically relates to the abuse and/or non-medical use of such. As mentioned above, for the sake of comparison, we also estimate the demand for cannabis, speed and ecstasy. Specifically, the unobserved latent propensity for drug $d$ consumption is linearly related to a set of observed characteristics such that

$Y_{d}^{*}=X \beta+u$

where $\beta$ is a vector of parameters to be estimated, and $u$ is a standard normally distributed error term. The vector $X$ also includes a set of dummy variables related to the industry and occupation in which the individual is employed. This gives rise to a standard Probit specification for the observed binary stochastic variable $Y_{d}$. 
The selection equation models the likelihood of being employed. As standard in the literature, the propensity to work is a linear function of observed characteristics $Z$ thus

$Y_{s}^{*}=Z \gamma+v$

with unknown weights $\gamma$ and a normally distributed error term $v$. This results in a standard Probit specification for another observed binary stochastic variable $Y_{s}$ that indicates whether the individual is employed or not. As both of the endogenous equations of interest here are binary, this set-up differs from the usual Heckit in that the system of two equations is estimated simultaneously via two correlated Probit equations. A priori one would expect that the disturbance terms in the two equations are correlated via unobserved factors (Johnson and Creech 1983), such as risk attitudes or motivation. ${ }^{4}$

The model is highly non-linear which facilitates identification. To further assist with identification we also use exclusion restrictions, that is, valid instruments are included in the selection equation but not the participation equation (see, for example, Wooldridge, 2010). It is often difficult to find such plausible variables and, as a result, selection models are frequently estimated with the same set of explanatory variables in both stages (Jones 2007), where identification relies solely on functional form. Here, we use the state-level job vacancy rate (that varies across the years), as the exclusion restriction in the drug equation. Naturally, the local availability of jobs greatly influences an individual's propensity to work (Howe and Connor 1982). At the same time it is unlikely that the job vacancy rate has any direct effect on an individual's drug participation decision.

To increase the explanatory power of the model, we also include the price of the drug as an instrument in the respective participation equations. Price provides a logical exclusion restriction as it is likely to influence an individual's decision to consume but has no direct effect on their propensity to be employed. It is commonly known that price information on illicit drugs is not easily obtained. Thus, the availability and inclusion of price data into the empirical analysis is an important feature of our study. The price data are merged in from a variety of sources. ${ }^{5}$ Importantly, pharmaceutical prices are adapted from the Australian

\footnotetext{
${ }^{4}$ Indeed the value of the correlation $\rho$ we estimate is -0.3 and statistically significant. This suggests the presence of endogenous sample selection and hence highlights the importance of controlling for such.

${ }^{5}$ State level prices for cannabis and speed are obtained from the Illicit Drug Reporting System (IDRS). The IDRS collects price information through, interviews with injecting drug users (IDU) and key informants who have regular contact with users, and the examination of extant data. The price of cannabis is measured in (log) dollars per ounce and the price of speed in (log) dollars per gram. The price of ecstasy is obtained from the Ecstasy and Related Drugs Reporting System (EDRS) which is administered in very much the same way as the
} 
Statistics on Medicines (ASM) reports. The ASM provides prescription numbers and total cost to both patient and government for all drugs listed as part of the Pharmaceutical Benefits Scheme (PBS). This information provides a proxy for price for several drugs in the painkiller/analgesics, tranquillisers/sleeping pill, steroids or other opiate categories that are included into the broad pharmaceuticals class to be examined. The pharmaceutical price is then determined via a (logged) weighted average of the price of the two most commonly used drugs in each class.

In terms of the other control variables, we follow the existing literature (see, for example, Cameron and Williams 2001, Ramful and Zhao 2009, Brown et al. 2013) and include: gender; age; whether the individual is of Aboriginal or Torres Strait Islander descent; whether the individual resides in a capital city; is married or cohabiting; comes from a single parent household; whether or not there are preschool aged children in the household; educational attainment distinguishing between four categories of highest educational attainment: a tertiary degree, a non-tertiary diploma or trade certificate, year 12 education, and less than year 12 education, which is the omitted category; the natural logarithm of real personal annual income before tax measured in Australian Dollars and the individual's main labour market status. Finally, for our analysis of the sample of employed individuals, we focus on industry and occupation effects, the classifications, based on the Australian and New Zealand Standard Industrial Classification (ANZSIC) and the Australian and New Zealand Standard Classification of Occupations (ANZSCO), are detailed below.

\section{Industry and occupation effects: A descriptive analysis}

Before conducting our statistical analysis, we were aware from previous literature that drug use is relatively more prevalent within the hospitality, construction, arts and recreation, agriculture and financial industries. When we break down the rates of drug use among the workforce according to worker's industry, the data that we used in our analysis are generally consistent with these previous findings, as shown in Figure 2.

IDRS. Ecstasy price is measured in (log) dollars per pill. While these prices are unlikely to be precise, they provide a close approximation of actual street price. All price series are deflated using the all-items consumer price index for the respective states (ABS 2014). 
Figure 2: Rates of drug use among Australian workforce, by industry of employment

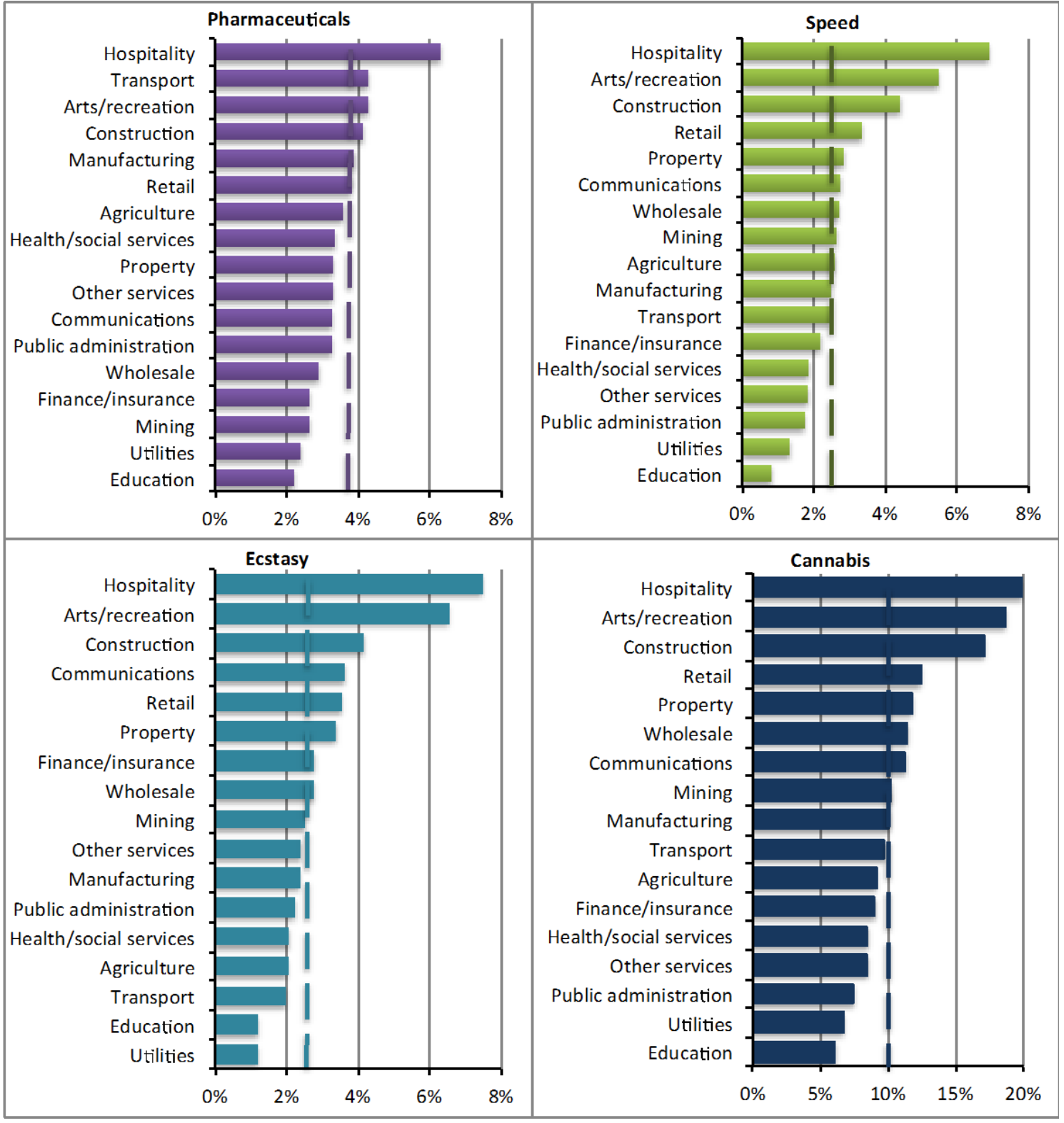

Note: Dotted lines represent the average rate across all industries, for the respective drug.

The highest rates of pharmaceutical drug misuse are reported in hospitality (6.3\%), transport (4.3\%), arts and recreation (4.3\%) and construction (4.2\%). Rates are lowest in education and training (2.2\%) and utilities (2.4\%). These industry-specific differentials are generally mirrored in patterns of illicit drug consumption. Across most industries, rates of pharmaceutical drug use are generally higher than rates of use of speed and ecstasy, although they are much lower than rates of cannabis use.

Previous studies have identified that drug use is higher in some occupations due to the stressful or demanding nature of the work undertaken. For example, drug use is common 
among truck drivers, as a means of overcoming the fatigue experienced during long-haul trips. Consumption of drugs in the workplace has also been found to be more common among blue-collar occupations in comparison to white-collar occupations, and among relatively lower skilled workers such as labourers, which again could also be attributed to the physically demanding nature of these jobs.

Figure 3: Rates of drug use among Australian workforce, by occupation

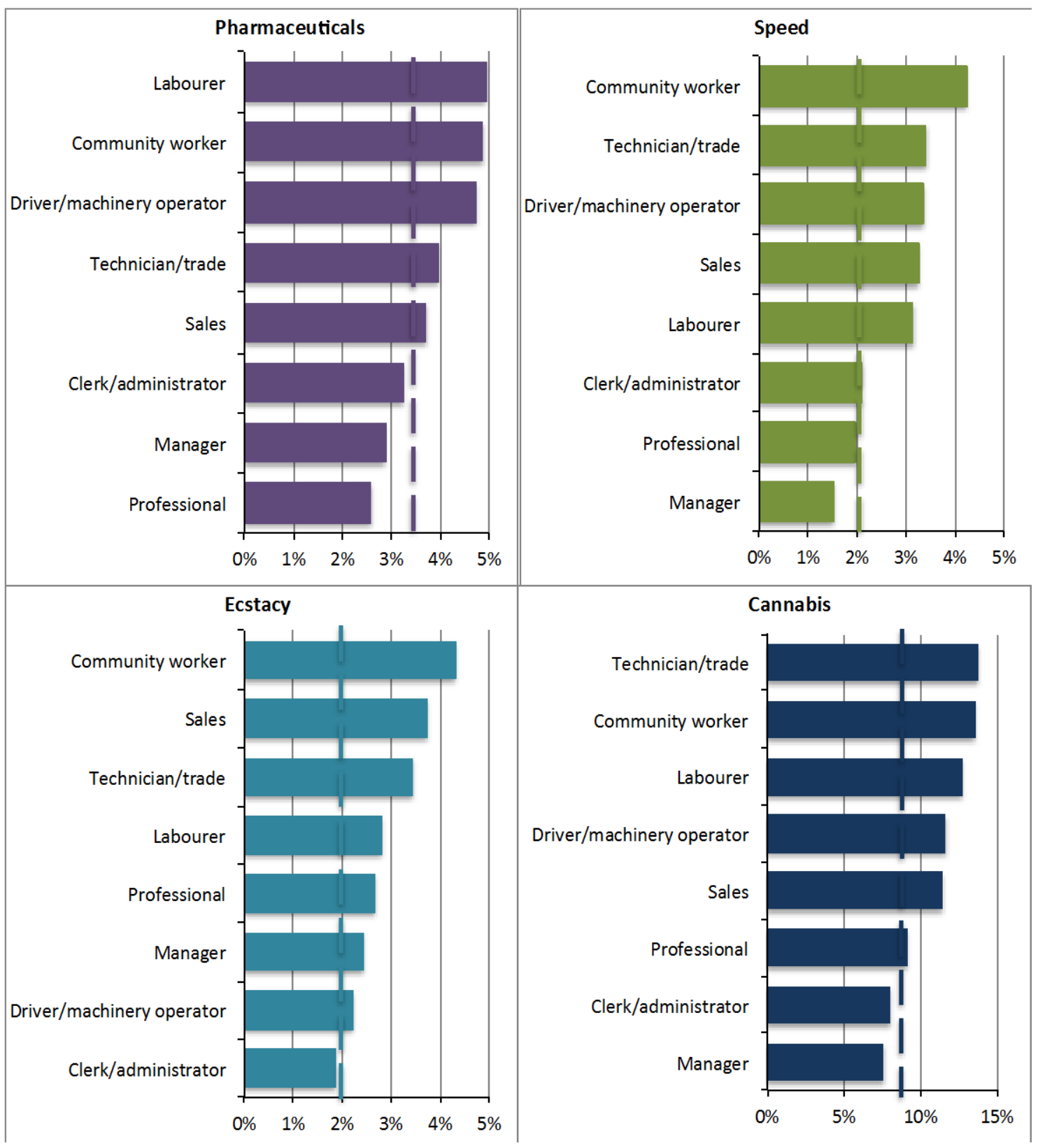

Note: Dotted lines represent the average rate across all occupations, for the respective drug.

Our profile of the Australian workforce shows clear differences in pharmaceutical drug misuse between workers on the basis of their occupation, as depicted in Figure 3. Higher 
rates are observed among community service workers (4.9\%), labourers (4.9\%) and, drivers and machine operators (4.8\%). On the other hand, managers and professionals, which are higher-skilled occupations, display the lowest rates of consumption $(2.9 \%$ and $2.6 \%$ respectively).

The econometric model that we estimate in the next section can be used to isolate the partial correlation between drug use and industry of employment and occupation, controlling for other factors such as age, education and income.

\section{Estimated Results}

\subsection{Industry Effects}

We apply the statistical techniques outlined in Section 4 to measure the likelihood that a worker in a particular industry misuses pharmaceutical drugs, while controlling for their other personal characteristics. $^{6,7}$ We use 'other services' as the reference category, against which all the other industries can be compared. Our measurements of industry effects are presented in Table 1. We find that the likelihood of pharmaceutical drug misuse is statistically higher in the hospitality industry: the partial effect of being employed in hospitality suggests that the probability that a worker will engage in pharmaceutical drug misuse is one percentage point higher, compared with the base group. Workers in the hospitality industry are also more likely than other workers to use cannabis, speed and ecstasy. In contrast, workers employed in the retail trade or finance and insurance industries are less likely to be misusing pharmaceutical drugs. For all the other industries, no statistically significant difference could be detected in rates of pharmaceutical drug consumption between that particular industry and the reference category.

Our findings are consistent with previous studies that identify hospitality workers as a high-risk group with regard to alcohol and other drug use in the workplace. Ease of

\footnotetext{
${ }^{6}$ For brevity, we do not present the results related to our control variables. They are available in Brown et al. (2015). In brief, our results show that individuals have a higher probability of engaging in pharmaceutical drug misuse if they have the following characteristics: younger in age; male; not married; no preschool-aged children; Aboriginal descent; living in a capital city; lower income; lower educational attainment; unemployed; and not a student. The probability of pharmaceutical drug misuse was found to be unaffected by whether or not a person lived in a single parent household, or their main language spoken at home, although these characteristics did exert an impact on the likelihood of using the other illicit drugs. The analysis also detected a negative relationship between the price of drugs and consumption.

${ }^{7}$ Note that our analysis serves to reveal correlations rather than causal relationships with drug use.
} 
availability and exposure to drugs within this industry may contribute to hospitality workers’ higher rate of use. The fact that the hospitality industry revolves around socialisation, frequently involving the widespread consumption of alcohol and cigarettes by customers, may heighten the probability of workers in the industry being attracted to use recreational drugs.

Table 1: Estimated Partial Effects of Industry on Illicit Drug Participation Rates

\begin{tabular}{lclllllll}
\hline & & & \multicolumn{1}{c}{ Pharmaceuticals } & \multicolumn{2}{c}{ Cannabis } & \multicolumn{2}{c}{ Speed } & \multicolumn{2}{c}{ Ecstasy } \\
\hline Agriculture & -0.008 & {$[0.007]$} & -0.003 & {$[0.011]$} & 0.006 & {$[0.005]$} & 0.007 & {$[0.006]$} \\
Mining & -0.009 & {$[0.008]$} & -0.005 & {$[0.014]$} & -0.002 & {$[0.007]$} & -0.003 & {$[0.007]$} \\
Manufacturing & -0.003 & {$[0.004]$} & 0.015 & {$[0.006]^{* *}$} & 0.003 & {$[0.003]$} & -0.000 & {$[0.003]$} \\
Utilities & -0.018 & {$[0.012]$} & -0.025 & {$[0.017]$} & -0.016 & {$[0.010]$} & -0.023 & {$[0.011]^{* *}$} \\
Construction & -0.004 & {$[0.004]$} & 0.054 & {$[0.007]^{* * *}$} & 0.015 & {$[0.003]^{* * *}$} & 0.011 & {$[0.003]^{* * *}$} \\
Wholesale trade & -0.011 & {$[0.007]$} & 0.019 & {$[0.011]^{*}$} & 0.006 & {$[0.006]$} & 0.004 & {$[0.006]$} \\
Retail trade & -0.007 & {$[0.004]^{*}$} & 0.007 & {$[0.006]$} & -0.002 & {$[0.003]$} & -0.003 & {$[0.003]$} \\
Hospitality & 0.010 & {$[0.004]^{* *}$} & 0.062 & {$[0.008]^{* * *}$} & 0.021 & {$[0.004]^{* * *}$} & 0.026 & {$[0.004]^{* * *}$} \\
Transport & 0.006 & {$[0.004]$} & 0.011 & {$[0.008]$} & 0.007 & {$[0.004]^{*}$} & 0.004 & {$[0.004]$} \\
Communications & 0.003 & {$[0.006]$} & 0.044 & {$[0.011]^{* * *}$} & 0.008 & {$[0.005]$} & 0.014 & {$[0.005]^{* * *}$} \\
Finance/insurance & -0.010 & {$[0.006]^{*}$} & 0.007 & {$[0.009]$} & 0.000 & {$[0.004]$} & 0.003 & {$[0.004]$} \\
Property & -0.003 & {$[0.004]$} & 0.016 & {$[0.006]^{* * *}$} & -0.001 & {$[0.003]$} & 0.002 & {$[0.003]$} \\
Public administration & -0.004 & {$[0.004]$} & -0.013 & {$[0.007]^{*}$} & -0.003 & {$[0.003]$} & -0.002 & {$[0.003]$} \\
Education & -0.007 & {$[0.004]$} & -0.012 & {$[0.007]^{*}$} & -0.014 & {$[0.004]^{* * *}$} & -0.010 & {$[0.004]^{* *}$} \\
Health/social services & -0.001 & {$[0.003]$} & 0.005 & {$[0.006]$} & 0.001 & {$[0.003]$} & 0.002 & {$[0.003]$} \\
Arts and recreation & 0.001 & {$[0.007]$} & 0.066 & {$[0.011]^{* * *}$} & 0.015 & {$[0.005]^{* * *}$} & 0.021 & {$[0.005]^{* * *}$} \\
\hline
\end{tabular}

Note: 'None' denotes that no statistically significant difference was detected. Differences are relative to the 'other services' industry which is used as the reference category. Standard errors in parentheses. ${ }^{* * *} \mathrm{p}<0.01,{ }^{* *} \mathrm{p}<0.05,{ }^{*} \mathrm{p}<0.1$.

While previous studies have detected a positive relationship between drug use and the construction industry - possibly attributable to the physically demanding, stressful and transient, stop-start nature of work in this industry - our analysis did not detect a higher probability of pharmaceutical drug misuse among construction workers. However, a strong positive relationship was confirmed with respect to the consumption of other illicit drugs within this industry.

Another industry that has been identified in previous studies as a high-risk industry is agriculture, due to the negative feelings of low self-worth that workers in the industry tend to experience. The finance industry has also been found to be associated with higher drug-taking in previous studies. Our analysis, however, did not detect a higher rate of drug-taking among agricultural nor finance workers when controlling for all other personal characteristics. 


\subsection{Occupation Effects}

Next, we estimate the model to examine the relationship between misuse of pharmaceutical drugs and occupation of employment. Again, we include a range of personal characteristics in our statistical analysis, so that we are isolating specific differences between workers only on the basis of their occupation. Our reference group, for comparison purposes, is 'labourers'.

Table 2: Estimated Partial Effects of Occupation on Illicit Drug Participation Rates

\begin{tabular}{|c|c|c|c|c|c|c|c|c|}
\hline \multirow[b]{2}{*}{ Manager } & \multicolumn{2}{|c|}{ Pharmaceuticals } & \multicolumn{2}{|c|}{ Cannabis } & \multicolumn{2}{|c|}{ Speed } & \multicolumn{2}{|c|}{ Ecstasy } \\
\hline & -0.007 & {$[0.004]^{*}$} & -0.004 & {$[0.006]$} & 0.000 & {$[0.003]$} & 0.004 & {$[0.003]$} \\
\hline Professional & -0.011 & {$[0.003]^{* * *}$} & -0.002 & {$[0.005]$} & -0.000 & {$[0.003]$} & -0.002 & [0.003] \\
\hline Technician/trade worker & -0.004 & {$[0.003]$} & 0.017 & {$[0.006]^{* * *}$} & 0.005 & {$[0.003]^{*}$} & 0.002 & [0.003] \\
\hline Clerk/administrator & -0.007 & {$[0.003]^{* *}$} & -0.004 & {$[0.006]$} & -0.002 & {$[0.003]$} & -0.009 & {$[0.003]^{* * *}$} \\
\hline Community service worker & 0.004 & {$[0.003]$} & -0.003 & {$[0.006]$} & 0.006 & {$[0.003]^{*}$} & 0.004 & {$[0.003]$} \\
\hline Sales worker & -0.007 & {$[0.004]^{* *}$} & -0.008 & {$[0.006]$} & -0.001 & {$[0.003]$} & 0.000 & [0.003] \\
\hline Driver/Machine Operator & 0.005 & {$[0.004]$} & 0.007 & [0.007] & 0.007 & {$[0.004]^{* *}$} & -0.004 & {$[0.004]$} \\
\hline
\end{tabular}

As shown in Table 2, some statistically significant differences among occupational groups are evident. Managers, professionals, clerks/administrators and sales workers are less likely to engage in pharmaceutical drug misuse, by a margin of between 0.7 and 1.1 percentage points. By comparison, technicians, trade workers, community workers, machine operators/drivers are found to be no different to the base group of labourers. These findings point towards a clear disparity in pharmaceutical drug misuse between white-collar and bluecollar occupations. These results align with previous studies that infer that the physicallydemanding nature of blue-collar jobs could be a factor behind workers' drug use. It could also be that the relatively cheaper cost of pharmaceuticals, compared to illicit drugs, could make pharmaceuticals a more accessible option among lower-skilled workers.

Our analysis also shows that illicit drug use is higher in particular occupations. For example, technicians/trade workers are statistically more likely to take cannabis and speed, even though they were found to be no different to labourers with respect to pharmaceutical drug misuse.

\subsection{Joint Industry and Occupation Effects}

We next include variables for both industry and occupation simultaneously. Table 3 presents the estimated effects. The analysis reinforces the finding that, in terms of industry, working in 
hospitality remains a strong predictor that a worker will be more likely to engage in pharmaceutical drug misuse. The effect of working in hospitality retains its strong link to the likelihood of engaging in illicit drug use too. In terms of occupation, the effect of working in a professional and clerical/administrative role is still found to be inversely associated with the likelihood of pharmaceutical drug misuse.

Table 3: Estimated Partial Effects of Industry \& Occupation on Illicit Drug Participation Rates

\begin{tabular}{|c|c|c|c|c|c|c|c|c|}
\hline \multirow{2}{*}{ Industry } & \multicolumn{2}{|c|}{ Pharmaceuticals } & \multicolumn{2}{|c|}{ Cannabis } & \multicolumn{2}{|c|}{ Speed } & \multicolumn{2}{|c|}{ Ecstasy } \\
\hline & & & & & & & & \\
\hline Agriculture & -0.008 & {$[0.007]$} & -0.003 & {$[0.011]$} & 0.006 & {$[0.006]$} & 0.006 & {$[0.006]$} \\
\hline Mining & -0.010 & {$[0.009]$} & -0.007 & {$[0.014]$} & -0.003 & [0.007] & -0.003 & [0.007] \\
\hline Manufacturing & -0.003 & {$[0.004]$} & 0.013 & {$[0.006]^{* *}$} & 0.002 & {$[0.003]$} & -0.000 & {$[0.003]$} \\
\hline Utilities & -0.016 & {$[0.012]$} & -0.026 & {$[0.017]$} & -0.016 & {$[0.010]$} & -0.022 & {$[0.011]^{*}$} \\
\hline Construction & -0.004 & [0.004] & 0.051 & {$[0.007]^{* * *}$} & 0.014 & {$[0.003]^{* * *}$} & 0.011 & {$[0.003]^{* * *}$} \\
\hline Wholesale trade & -0.010 & [0.007] & 0.020 & {$[0.011]^{*}$} & 0.005 & {$[0.006]$} & 0.004 & {$[0.006]$} \\
\hline Retail trade & -0.005 & {$[0.004]$} & 0.008 & {$[0.006]$} & -0.002 & {$[0.003]$} & -0.004 & {$[0.003]$} \\
\hline Hospitality & 0.010 & {$[0.005]^{* *}$} & 0.063 & {$[0.008]^{* * *}$} & 0.021 & {$[0.004]^{* * *}$} & 0.025 & {$[0.004]^{* * *}$} \\
\hline Transport & 0.003 & {$[0.005]$} & 0.008 & {$[0.008]$} & 0.005 & {$[0.004]$} & 0.005 & {$[0.004]$} \\
\hline Communications & 0.005 & {$[0.006]$} & 0.044 & {$[0.011]^{* * *}$} & 0.008 & [0.005] & 0.015 & {$[0.005]^{* * *}$} \\
\hline Finance/insurance & -0.007 & {$[0.006]$} & 0.008 & {$[0.009]$} & 0.001 & [0.004] & 0.004 & {$[0.004]$} \\
\hline Property & -0.000 & {$[0.004]$} & 0.016 & {$[0.006]^{* * *}$} & -0.001 & {$[0.003]$} & 0.003 & {$[0.003]$} \\
\hline Public administration & -0.002 & {$[0.004]$} & -0.013 & {$[0.007]^{*}$} & -0.003 & {$[0.004]$} & -0.001 & {$[0.003]$} \\
\hline Education & -0.004 & {$[0.004]$} & -0.011 & [0.007] & -0.015 & {$[0.005]^{* * *}$} & -0.010 & {$[0.004]^{* *}$} \\
\hline Health/social services & 0.000 & [0.003] & 0.006 & {$[0.006]$} & -0.000 & {$[0.003]$} & 0.001 & {$[0.003]$} \\
\hline Arts and recreation & 0.003 & {$[0.007]$} & 0.066 & {$[0.011]^{* * *}$} & 0.014 & {$[0.005]^{* * *}$} & 0.021 & {$[0.005]^{* * *}$} \\
\hline \multicolumn{9}{|l|}{ Occupation } \\
\hline Manager & -0.006 & {$[0.004]$} & -0.007 & {$[0.006]$} & -0.000 & {$[0.003]$} & 0.003 & {$[0.003]$} \\
\hline Professional & -0.011 & {$[0.003]^{* * *}$} & -0.002 & [0.005] & 0.001 & [0.003] & -0.002 & [0.003] \\
\hline Technician/trade worker & -0.003 & {$[0.003]$} & 0.006 & {$[0.006]$} & 0.003 & {$[0.003]$} & -0.000 & {$[0.003]$} \\
\hline Clerk/administrator & -0.006 & {$[0.003]^{*}$} & -0.004 & {$[0.006]$} & -0.001 & {$[0.003]$} & -0.010 & {$[0.003]^{* * *}$} \\
\hline Community service worker & 0.002 & {$[0.004]$} & -0.008 & {$[0.007]$} & 0.003 & {$[0.003]$} & 0.000 & {$[0.003]$} \\
\hline Sales worker & -0.006 & [0.004] & -0.008 & [0.007] & 0.001 & {$[0.003]$} & 0.002 & [0.003] \\
\hline Driver/Machine Operator & 0.005 & [0.004] & 0.009 & [0.008] & 0.007 & {$[0.004]^{*}$} & -0.004 & [0.004] \\
\hline
\end{tabular}

Note: 'None' denotes that no statistically significant difference was detected. Differences are relative to the 'other services' for industry and 'labourers' for occupation. Standard errors in parentheses. ${ }^{* * *} \mathrm{p}<0.01,{ }^{* *} \mathrm{p}<0.05,{ }^{*} \mathrm{p}<0.1$.

\subsection{Extensions}

To shed further light on the specific workplace characteristics driving the industry and occupation trends presented above, we extended our analysis of pharmaceutical drug misuse in several respects. Firstly, we examined whether the probability of pharmaceutical drug 
misuse varied over time. In this exercise we also interact the industries with year-based dummies to check if the time effects are industry-specific. These results are presented in Table 4.

Table 4: Estimated Interaction Effects of Industry with Time

\begin{tabular}{|c|c|c|c|c|c|c|c|c|}
\hline \multirow[b]{2}{*}{2004} & \multicolumn{2}{|c|}{ Base effect } & \multicolumn{2}{|c|}{ Industry*2004 } & \multicolumn{2}{|c|}{ Industry*2007 } & \multicolumn{2}{|c|}{ Industry*2010 } \\
\hline & 0.026 & {$[0.013]^{*}$} & & & & & & \\
\hline 2007 & 0.046 & {$[0.018]^{* *}$} & & & & & & \\
\hline 2010 & 0.043 & {$[0.020]^{* *}$} & & & & & & \\
\hline \multicolumn{9}{|l|}{ Industry } \\
\hline Agriculture & -0.018 & {$[0.022]$} & -0.028 & {$[0.032]$} & 0.029 & {$[0.027]$} & 0.016 & {$[0.030]$} \\
\hline Mining & -0.043 & [0.039] & 0.033 & {$[0.044]$} & 0.008 & {$[0.044]$} & 0.082 & {$[0.047]^{*}$} \\
\hline Manufacturing & 0.026 & {$[0.011]^{* *}$} & -0.032 & {$[0.016]^{* *}$} & -0.054 & {$[0.017]^{* * *}$} & -0.037 & {$[0.016]^{* *}$} \\
\hline Utilities & -0.005 & {$[0.031]$} & 0.018 & {$[0.040]$} & -0.053 & {$[0.050]$} & -0.437 & [0.427] \\
\hline Construction & 0.014 & {$[0.012]$} & -0.032 & {$[0.018]^{*}$} & -0.026 & [0.017] & -0.013 & {$[0.016]$} \\
\hline Wholesale trade & 0.013 & {$[0.020]$} & -0.039 & [0.029] & -0.020 & [0.027] & -0.050 & {$[0.032]$} \\
\hline Retail trade & 0.003 & {$[0.010]$} & -0.008 & {$[0.015]$} & -0.022 & [0.015] & -0.019 & {$[0.016]$} \\
\hline Hospitality & 0.031 & {$[0.014]^{* *}$} & -0.022 & {$[0.019]$} & -0.025 & [0.018] & -0.018 & {$[0.018]$} \\
\hline Transport & 0.014 & {$[0.013]$} & -0.005 & {$[0.018]$} & -0.016 & [0.018] & 0.003 & {$[0.016]$} \\
\hline Communications & 0.002 & {$[0.021]$} & -0.001 & {$[0.028]$} & -0.011 & [0.027] & 0.026 & {$[0.027]$} \\
\hline Finance/insurance & -0.008 & {$[0.016]$} & 0.003 & [0.021] & -0.019 & [0.023] & -0.001 & {$[0.026]$} \\
\hline Property & 0.010 & {$[0.010]$} & -0.017 & {$[0.015]$} & 0.009 & {$[0.023]$} & -0.017 & {$[0.014]$} \\
\hline Public administration & 0.017 & {$[0.011]$} & -0.029 & {$[0.017]^{*}$} & -0.026 & {$[0.016]^{*}$} & -0.032 & {$[0.016]^{*}$} \\
\hline Education & 0.015 & {$[0.011]$} & -0.025 & {$[0.016]$} & -0.049 & {$[0.018]^{* * *}$} & -0.001 & {$[0.021]$} \\
\hline Health/social services & 0.020 & {$[0.010]^{* *}$} & -0.021 & {$[0.014]$} & -0.033 & {$[0.014]^{* *}$} & -0.035 & {$[0.019]^{*}$} \\
\hline Arts and recreation & -0.008 & {$[0.019]$} & 0.018 & {$[0.024]$} & 0.015 & {$[0.027]$} & - & - \\
\hline
\end{tabular}

Note: 'None' denotes that no statistically significant difference was detected. Differences are relative to the 'other services' for industry, 'labourers' for occupation and year 2001. Standard errors in parentheses. ${ }^{* *} \mathrm{p}<0.01,{ }^{* *} \mathrm{p}<0.05,{ }^{*} \mathrm{p}<0.1$.

The inclusion of year-based dummies reveals that, relative to the starting year of our sample period (i.e. 2001), the likelihood of pharmaceutical drug misuse generally rose within the Australian workforce overall. ${ }^{8}$ Moreover, some of these time effects were industry specific. Of particular note, mining workers were 8.2 percentage points more likely to engage in this type of drug misuse in 2010, coinciding with the final stages of the mining boom. At the same time, however, we observe that construction workers had a lower likelihood of partaking in pharmaceutical drug use in 2004 - this might have also been related to the mining boom since the boom was largely construction-based during its early stages.

While being employed in the manufacturing industry is positively associated with pharmaceutical misuse, we find a negative trend over time. With the hospitality industry, while we observe a higher rate of misuse there is no specific time trend. The latter finding

\footnotetext{
${ }^{8}$ That is, in the years 2004, 2007 and 2010, relative to 2001.
} 
suggests that pharmaceutical drug misuse within the hospitality industry - which has already been identified as high-risk - has been persistently higher over our time period. Interestingly, in the three main industries that are public sector dominated - education, health and social services, and public administration - the probability of pharmaceutical drug misuse showed some decline over time. This could be an indication of the effect of workplace culture or regulatory settings prevailing within the public service. It is also interesting that, in contrast to overarching workforce trends, Australia's manufacturing industry was the only industry which shrunk in absolute size throughout the 2000. Possibly, workers' motivation to preserve their jobs amid precarious industry conditions deterred them from engaging in any risky activity such as drug misuse.

Secondly, in our extension of the analysis, we distinguished between blue and white collar workers as collective groups. We found that blue collar workers were 0.6 percentage point more likely to engage in pharmaceutical drug misuse. ${ }^{9}$ This finding was generally consistent with the specific occupation-based analysis presented earlier. This blue collar effect was not found to be industry-specific. Even with the inclusion of the blue collar variable, hospitality workers still stood out as the workers most likely to engage in this type of drug misuse.

Thirdly, we explored the possibility that workers in higher status, executive roles who carry greater decision-making authority and responsibility - might exhibit different behavior from other workers. ${ }^{10}$ The analysis showed that these higher status workers were less likely to engage in pharmaceutical drug misuse, by a margin of around $1 \%$. While the effect was mostly industry-independent we find some evidence of a lower misuse in the finance and insurance industry executives. Lastly, we explored whether workers in the mining-rich states of Western Australia and Queensland collectively exhibited different behaviour from those in all other states and territories, which could potentially indicate that more stringent regulations are in place in these states. However, no significant differentials were detected.

\footnotetext{
${ }^{9}$ Whereby 'blue collar' refers to technicians, trade worker, drivers, machine operators and labourers, and 'white collar' refers to all other occupations (as per the classifications used in ABS (2011) Australian Social Trends: Fifty Years of the Labour Force: Now and Then, December, Cat. no. 4102.0).

${ }^{10}$ We classified these higher status workers as managers and professionals, which correspond to the highest ranked skilled occupations (as per ABS (2013) Australian and New Zealand Standard Classification of Occupations (ANZSCO), Cat. no. 1220.0).
} 


\section{Conclusion}

Our findings help to identify the industry and occupational groups within the Australian workforce that have a greater propensity to use legally-prescribed and over-the-counter pharmaceutical drugs for non-medical purposes. Such behaviour is an obvious concern in the workplace, given the losses in productivity and workplace risks it creates. It is also a concern that such behaviour could be attributed to pressures or cultural norms that prevail in particular workplaces.

Our findings confirm that considerable differences in drug use exist on the basis of workers' industry and occupation of employment. Most notably, our findings consolidate previous studies that have identified hospitality as a particularly high risk industry, as well as blue-collar jobs. Contrastingly, jobs with higher responsibility and authority are inversely associated with such behaviour.

Our analysis has acknowledged that various measures are in place to monitor and deter drug misuse among workers, such as prohibitive legislation and guidelines to assist employers formulate their own drug testing policies. However, we also need to acknowledge the challenges involved in attempting to tackle this type of drug misuse. For a start, monitoring the consumption of legally-available products is difficult to carry out. Exacerbating the problem, the online availability of pharmaceutical drugs continues to grow over time. While law enforcement measures are unlikely to be effective in fully curbing pharmaceutical drug misuse among the general population, it is important that employers and workers alike continue to abide by workplace legislation and heed recommended policy guidelines, in order to ensure a safe working environment. Furthermore, there is likely to be merit in attempts to reduce demand for these products through incentive measures, such as the provision of education programs to workers. Workplace testing procedures also serve as an incentive against engaging in drug misuse, as it places workers' jobs at stake. An important step towards formulating these demand-reduction strategies is the collation of evidence and knowledge about which workers are most at risk. By providing a statistical profile of the prevalence of drug misuse among the Australian workforce, this study offers a useful contribution towards this knowledge base and a platform on which policies to tackle this issue can be built. 


\section{References}

ABS (Australian Bureau of Statistics) (2011): Household Use of Information Technology.

Cat. No. 8146.0, Australia Bureau of Statistics, Canberra.

ABS (2014): Consumer Price Index, Cat. No. 6401.0, Australian Bureau of Statistics.

ACC (2006): “Illicit Drug Data Report 2004-05,” Australian Crime Commission.

Commonwealth of Australia: Canberra.

AIHW (Australian Institute of Health and Welfare) (2011): 2010 National Drug Strategy Household Survey Report, Australian Institute of Health and Welfare, Canberra.

Ames, G. and J. Grube (1999): “Alcohol Availability and Workplace Drinking: Mixed Method Analyses,” Journal of Studies on Alcohol 60(3): 383-393.

Ames, G., J. Grube, and R. Moore (2000): "Social Control and Workplace Drinking Norms: A Comparison of Two Organizational Cultures," Journal of Studies on Alcohol and Drugs, 61(2), 203.

Bacharach, S., P. Bamberger and W. Sonnenstuhl (2002): "Driven to Drink: Managerial Control, Work-Related Risk Factors, and Employee Problem Drinking,” The Academy of Management Journal, 45(4): 637-658.

Banwell, C. P. Dance, C. Quinn, R. Davies, and D. Hall (2006): “Alcohol, Other Drug Use, and Gambling Among Australian Capital Territory (ACT) Workers in the Buildinga Related Industries,” Drugs: Education, Prevention and Policy, 13(2): 167-178.

Berry, J., K. Pidd, A. Roche, and J. Harrison (2007): "Prevalence and Patterns of Alcohol Use in the Australian Workforce: Findings from the 2001 National Drug Strategy Household Survey,” Addiction, 102(9): 1399-1410.

Biggs, H., and A. Williamson (2012): "Safety Impacts of Alcohol and Other Drugs in Construction: Development of an Industry Policy and Cultural Change Management Program,” In Smith, S. (Ed.) ARCOM Proceedings of the $28^{\text {th }}$ Annual Conference. Association of Researchers in Construction Management (ARCOM), Edinburgh.

Biggs, H., and A. Williamson (2013): "Reducing the Risk of Alcohol and Other Drugs in Construction: An Australian Assessment,” In Yazdari, S. and Singh, A. (Eds.) New Developments in Structural Engineering and Construction. Research Publishing Services, Singapore.

Boye, M., and J. Jones (1997): “Organizational Culture and Employee Counter Productivity,” In Giacalone, R. and J. Greenberg, Antisocial Behaviour in Organizations: 172-184. California. 
Brown, S., M. Harris, and P. Srivastava (2013): "Modelling Illegal Drug Participation,” Bankwest Curtin Economics Centre Working series, WP1303, Australia.

Brown, S., M. Harris, J. Prendergast and P. Srivastava (2015): "Pharmaceutical Drug Misuse, Industry of Employment and Occupation,” Bankwest Curtin Economics Centre Working series, WP1501, Australia.

Cameron, L., and J. Williams (2001): "Cannabis, Alcohol and Cigarettes: Substitutes or Complements?” Economic Record, 77(236): 19-34.

Compton, W., and N. Volkow (2006): "Major Increases in Opioid Analgesic Abuse in the United States: Concerns and Strategies,” Drug and Alcohol Dependence, 81(2): 103-107.

Conway, T., R. Vickers Jr, H. Ward, and R. Rahe (1981): “Occupational Stress and Variation in Cigarette, Coffee, and Alcohol Consumption,” Journal of Health and Social Behavior, 22(2): 155-165.

Couper, F., M. Pemberton, A. Jarvis, M. Hughes, and B. Logan (2002): "Prevalence of Drug Use in Commercial Tractor-Trailer Drivers,” Journal of Forensic Sciences 47(3): 562-567.

DeSimone, J. (2002): “Illegal Drug Use and Employment,” Journal of Labor Economics, 20(4): 952-977.

Du Plessis, K., and T. Corney (2011): “Construction Industry Apprentices’ Substance Use: A Survey of Prevalence Rates, Reasons for Use, and Regional and Age Differences,” Youth Studies Australia 30(4): 40-50.

Eade, V. (1993): “Drug Abuse in the Hospitality Industry,” Hospitality Review 11(2): 81-86.

Evans, A., R. Tait, P. Harvey and J. Newbury (2005): "Recreational Drug Use Within the Employees of the Mariculture and Seafood Industry in South Australia,” Drug and Alcohol Review 24(1): 67-68.

Farrelly, M., J. Bray, G. Zarkin, B. Wendling, and R. Pacula (1999): “The Effects of Prices and Policies on the Demand for Marijuana: Evidence from the National Household Surveys on Drug Abuse,” NBER Working Paper No. 6940, National Bureau of Economic Research, Cambridge.

Farrelly, M., J. Bray, T. Pechacek, and T. Woollery (2001): "Response by Adults to Increases in Cigarette Prices by Socio-demographic Characteristics,” Southern Economic Journal, 68(1): 156-165.

Folkard, S., and T. Monk (1979): "Shiftwork and Performance," The Journal of the Human Factors and Ergonomics Society 21(4): 483-492.

Friedman, R. (2006): “The Changing Face of Teenage Drug Abuse -The Trend Toward Prescription Drugs,” New England Journal of Medicine, 354(14): 1448. 
Galea, S., Nandi, A., and D. Vlahov (2004): “The Social Epidemiology of Substance Use,” Epidemiologic Reviews, 26(1), 36-52.

Gleason, P., J. Veum, and M. Pergamit (1991): “Drug and Alcohol Use at Work: A Survey of Young Workers,” Monthly Labor Review, 114(8): 3-7.

Grossman, M., and F. Chaloupka (1998): “The Demand for Cocaine by Young Adults: A Rational Addiction Approach,” Journal of Health Economics, 17(4): 427-474.

Hando, J., B. Flaherty, and S. Rutter (1997): "Research Report: An Australian Profile on the Use of Cocaine,” Addiction, 92(2), 173-182.

Harris, M., and X. Zhao (2007): “A Zero-Inflated Ordered Probit Model, with an Application to Modelling Tobacco Consumption,” Journal of Econometrics, 141(2): 1073-1099.

Howe, A., and K. O’Connor, (1982): “Travel to Work and Labor Force Participation of Men and Women in an Australian Metropolitan Area,” The Professional Geographer 34(1): 5064.

Johnson, D., and J. Creech (1983): “Ordinal Measures in Multiple Indicator Models: A Simulation Study of Categorization Error,” American Sociological Review 48(3): 398-407.

Jones, A. (2007): Applied Econometrics for Health Economists: A Practical Guide. $2^{\text {nd }}$ Ed. Radcliffe Publishing Ltd, Oxon.

Krueger, G. (1989): "Sustained Work, Fatigue, Sleep Loss and Performance: A Review of the Issues,” Work and Stress 3(2): 129-141.

Larsen, S. (1994): “Alcohol Use in the Service Industry,” Addiction, 89(6):733-741.

Lye, J., and J. Hirschberg (2010): “Alcohol Consumption and Human Capital: A Retrospective Study of the Literature,” Journal of Economic Surveys 24(2): 309-338.

Macdonald, Z., and S. Pudney (2000): "Illicit Drug Use, Unemployment, and Occupational Attainment,” Journal of Health Economics, 19(6): 1089-1115.

Macdonald, Z., and M. Shields (2000): “The Impact of Alcohol Consumption on Occupational Attainment in England,” Economica, 68(271): 427-453.

McCarthy, M. (2007): "Prescription Drug Abuse Up Sharply in the USA," The Lancet, 369(9572): 1505-1506.

Monk, T., and S. Folkard (1985): "Individual Differences in Shiftwork Adjustment, in S. Folkard and T. Monk (eds), Hours of Work: Temporal Factors in Work Scheduling (New York: Wiley).

NDSHS (2010): Computer Files for the Unit Record Data from the National Drug Strategy Household Surveys, Social Science Data Archives, Australian National University, Canberra. 
Nielsen, S., and M. Barratt (2009): “Prescription Drug Misuse: Is Technology Friend or Foe?” Drug and Alcohol Review, 28(1): 81-86.

NSDUH (2013): Results from the 2013 National Survey on Drug Use and Health: Summary of National Findings, http://www.samhsa.gov/data/NSDUH/2013SummNatFindDetTables/NationalFindings/NS DUHresults2013.htm

Pidd, K., J. Berry, A. Roche and J. Harrison (2006): "Estimating the Cost of Alcohol-Related Absenteeism in the Australian Workforce: the Importance of Consumption Patterns,” The Medical Journal of Australia, 185(11): 637-641.

Pidd, K., A. Roche, and F. Buisman-Pijlman (2011): "Intoxicated Workers: Findings from an Australian Survey,” Addiction 106(9): 1623-1633.

Ramful, P., and X. Zhao (2009): "Participation in Marijuana, Cocaine and Heroin Consumption in Australia: a Multivariate Probit Approach,” Applied Economics, 41(4): 481-496.

Register, C., and D. Williams (1992): “Labor Market Effects of Marijuana and Cocaine Use Among Young Men,” Industrial and Labor Relations Review 45(3): 435-448.

Silva, O., J. Greve, M. Yonamine, and V. Leyton (2003): "Drug Use by Truck Drivers in Brazil,” Drugs: Education, Prevention and Policy, 10(2): 135-139.

Twombly, E., and K. Holtz (2008): "Teens and the Misuse of Prescription Drugs: EvidenceBased Recommendations to Curb a Growing Societal Problem,” The Journal of Primary Prevention, 29(6): 503-516.

Trinkoff, A. M., C. Storr, and P. Wall, (1999): "Prescription-type drug misuse and workplace access among nurses,” Journal of Addictive Diseases, 18(1): 9-17.

Vaidya, J., R. Block, D. O’Leary, L. Ponto, M. Ghoneim and A. Bechara (2012): “Effects of Chronic Marijuana Use on Brain Activity during Monetary Decision-Making,” Neuropsychopharmacology 37(3): 618-629.

Williams, J. (2004): "The Effects of Price and Policy on Marijuana Use: What Can Be Learned from the Australian Experience?" Health Economics, 13(2): 123-137.

Wooldridge, J. (2010), Econometric Analysis of Cross-Section and Panel Data. MIT Press, Cambridge, MA.

Zarkin, G., M. French, T. Mroz, and J. Bray (1998): “Alcohol Use and Wages: New Results from the National Household Survey on Drug Abuse," Journal of Health Economics, 17(1): 53-68. 
Zhang, Z., and W. Snizek (2003): “Occupation, Job Characteristics, and the Use of Alcohol and Other Drugs,” Social Behavior and Personality: An International Journal, 31(4): 395412.

Zhao, X. and M. Harris (2004): “Demand for Marijuana, Alcohol and Tobacco: Participation, Levels of Consumption and Cross-equation Correlations,” Economic Record, 80(251): 394-410. 